\title{
DESIGN OF TRIBAND WILKINSON POWER DIVIDER USING EXTENDED T- SHAPED STUBS
}

\author{
Sandra Brigit Johnson ${ }^{1}$, Saranya Nath $\mathbf{P}^{2}$ \\ ${ }^{1,2}$ M.Tech Student, SENSE School, VIT University, Vellore, India
}

\begin{abstract}
A modified unequal Wilkinson power divider (WPD) with triband operation is presented in this paper. For triband operation, the quarter wave branch lines in the conventional WPD are replaced with extended T-shaped open or short stubs. In the proposed structure, the operating frequencies can be flexibly controlled, provided the second frequency is the mean of the first and third frequencies. The design equations for the structure and the design procedures are well explained in this paper. A sample prototype with the power dividing ratio of $2: 1$ and operating frequencies of 1.3, 3.0 and 4.7GHz has been designed, measured and compared. The microstrip circuit with substrate thickness $(h)$ of $0.813 \mathrm{~mm}$ and dielectric constant ( $\left.\varepsilon_{r}\right)$ of 3.55 is analyzed using AWR software. The frequency response characteristic in terms of return loss reveals that the short stub design gives a better performance in comparison with the open stub design.
\end{abstract}

Keywords: Triband, T-shaped stubs and unequal Wilkinson power divider

\section{INTRODUCTION}

Power dividers are passive microwave components used for power division or power combining. It is widely used in microwave power amplifier linearization, high power transmitter, antenna array feed networks and in calibration laboratories. Power dividers are often of the equal division (3dB) type, but unequal power division ratios are also possible. [3]The Wilkinson power dividers are widely used because it provides better isolation between the output ports. In order to be compliant with several communication systems, multiband microwave circuits are required for size and cost reduction. The conventional Wilkinson power divider utilizing a quarter- wavelength transformer can only be operated at a single frequency and its odd harmonics.

This paper proposes a tri-band Wilkinson power divider using extended T-shaped short and open stub structures. Design equations are obtained by performing the network analysis using the ABCD parameters. For analysis, a triband Wilkinson power divider operating at $1.3,3.0$ and $4.7 \mathrm{GHz}$ was designed and frequency response characteristics of both the structures are compared.

\section{STRUCTURE AND THEORY}

\subsection{Conventional Unequal Wilkinson Power}

\section{Divider (WPD)}

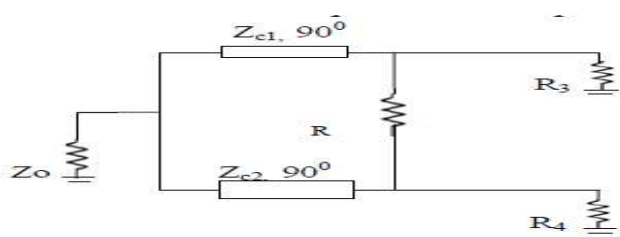

Fig -1: Conventional WPD
A conventional unequal WPD is shown in figure $1 . Z_{c 1}$ and $\mathrm{Z}_{\mathrm{c} 2}$ denotes the two quarter wavelength branch lines. [3]The design equations are as follows

$$
\begin{gathered}
\mathrm{Zc} 1=\mathrm{Z} 0 \sqrt{ }(\mathrm{k}(1+\mathrm{k} 2)) \\
\mathrm{Zc} 2=\mathrm{Z} 0 \sqrt{ }((1+\mathrm{k} 2) / \mathrm{k} 3) \\
\mathrm{R}=\mathrm{Z} 0(\mathrm{k} 2+1) / \mathrm{k} \\
\mathrm{R} 3=\mathrm{Z} 0 \sqrt{\mathrm{k}} \\
\mathrm{R} 4=\mathrm{Z} 0 / \sqrt{\mathrm{k}}
\end{gathered}
$$

Where $\mathrm{k}^{2}$ denotes the power dividing ratio and $\mathrm{Z}_{0}$ is the port impedance.

\subsection{Tri-Band Unequal Wilkinson Power Divider} (WPD)

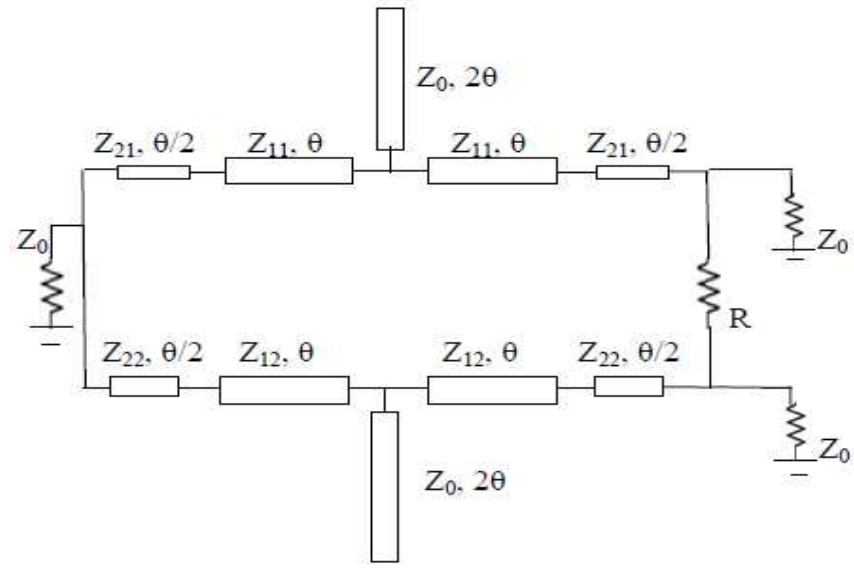

Fig -2: A triband unequal WPD (using open stub) 
[1]The tri-band operation can be achieved by replacing the quarter wavelength branch lines in a conventional WPD by extended T-shaped open/short stub[2].The equivalence between the conventional $\lambda / 4$ line and the extended $\mathrm{T}$ shaped stubs is shown below.

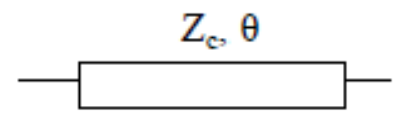

(a) Quarter- wavelength transmission line

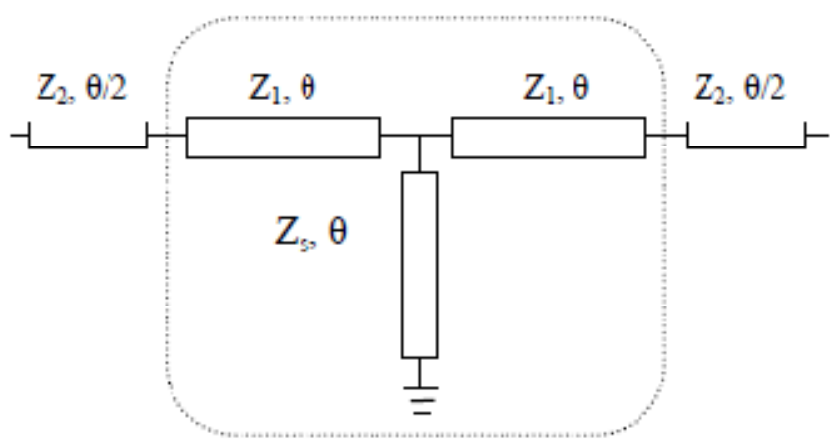

(b) Extended T-shaped short stub

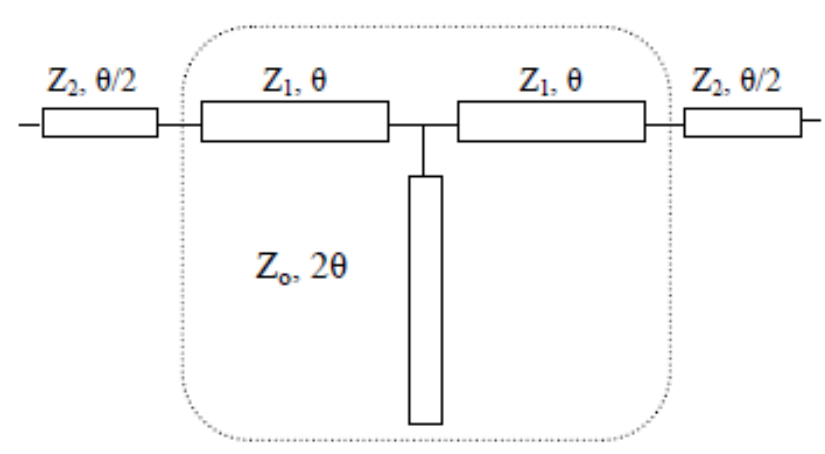

(c) Extended T-shaped open stub

Fig - 3: A quarter wavelength transmission line and its Tstub equivalents

The above rectangular areas (in dashed lines) can be designed to obtain the dual band operation. The extended transmission lines $\left(Z_{2}, \theta / 2\right)$, cascaded to the T-stub corresponds to the third band. The stubs are tapped at the center of the transmission line sections.

\subsubsection{The Extended T-Shaped Short Stub}

The $[A B C D]$ matrix of the structure in figure $3(b)$ can be represented as[2]

$$
\left(\begin{array}{ll}
A & B \\
C & D
\end{array}\right)=\mathrm{A}_{1} \mathrm{~A}_{2} \mathrm{~A}_{\mathrm{S}} \mathrm{A}_{2} \mathrm{~A}_{1}
$$

Where

$$
\mathrm{A}_{1}=\left(\begin{array}{cc}
\cos \frac{\theta}{2} & j Z_{2} \sin \frac{\theta}{2} \\
j \sin \theta / 2 & \cos \frac{\theta}{2}
\end{array}\right)
$$

$$
\begin{aligned}
\mathrm{A}_{2}= & \left(\begin{array}{cc}
\cos \theta & j Z_{1} \sin \theta \\
\frac{j \sin \theta}{Z_{1}} & \cos \theta
\end{array}\right) \\
\mathrm{A}_{\mathrm{s}} & =\left(\begin{array}{cc}
1 & 0 \\
\frac{-j \cot \theta}{z_{s}} & 1
\end{array}\right)
\end{aligned}
$$

Now the $[A B C D]$ matrix of a quarter wave transmission line can be written as

$$
\left(\begin{array}{cc}
A_{c} & B_{c} \\
C_{c} & D_{c}
\end{array}\right)=\left(\begin{array}{cc}
0 & j Z_{c} \\
\frac{j}{Z_{c}} & 0
\end{array}\right)
$$

Then by equating $(6)=(1)$, we have

$$
\begin{gathered}
Z_{1}=\frac{Z_{C} Z_{2}-Z_{2}^{2} \tan \frac{\theta}{2}}{Z_{2} \tan \theta+Z_{C} \tan \theta \tan \frac{\theta}{2}} \\
Z_{S}=-\frac{Z_{2}\left(Z_{2} \tan \frac{\theta}{2}+Z_{C}\right)-Z_{1}\left(Z_{c} \tan \frac{\theta}{2}-Z_{2}\right) \tan \theta}{Z_{2}\left(Z_{1}-Z_{C} \tan \theta\right)-\left(Z_{2}{ }^{2} \tan \theta+Z_{c} Z_{1}\right) \tan \theta / 2} \frac{Z_{1}}{2 \tan \theta}
\end{gathered}
$$

\subsubsection{The Extended T-Shaped Open Stub}

[2]The $[A B C D]$ matrix of the structure in figure 3(c) can be represented as

$$
\left(\begin{array}{ll}
A^{\prime} & B^{\prime} \\
C^{\prime} & D^{\prime}
\end{array}\right)=A_{1} A_{2} A_{O} A_{2} A_{1}
$$

Where

$$
A_{0}=\left(\begin{array}{cc}
1 & 0 \\
\frac{j \tan \theta}{z_{0}} & 1
\end{array}\right)
$$

Similarly, by equating $(10)=(13)$, we have

$$
Z_{0}=\frac{Z_{2}\left(Z_{2} \tan \frac{\theta}{2}+Z_{c}\right)-Z_{1}\left(Z_{c} \tan \frac{\theta}{2}-Z_{2}\right) \tan \theta}{Z_{2}\left(Z_{1}-Z_{c} \tan \theta\right)-\left(Z_{2}^{2} \tan \theta+Z_{c} Z_{1}\right) \tan \theta / 2} \frac{Z_{2} \tan 2 \theta}{2}
$$

For design simplicity, the extended line impedances are chosen to be equal to the conventional branch line impedances. Thus the equations (11), (12) and (15) can be simplified as

$$
\begin{gathered}
Z_{1}=\frac{Z_{c}(1-\sin \theta)}{\sin \theta} \\
Z_{s}=Z_{1} \frac{1-\sin \theta}{2 \sin \theta-1} \\
Z_{o}=2 Z_{1} \frac{(1-\sin \theta)\left(\sin ^{2} \theta\right)}{\cos 2 \theta(1-2 \sin \theta)}
\end{gathered}
$$


For unequal power division $Z_{c}$ becomes $Z_{c 1}$ and $Z_{c 2}$ depending on the power division ratio $\mathrm{k}^{2}$.

The electrical lengths $\theta_{\mathrm{L}}$ and $\theta_{\mathrm{U}}$ corresponds to the arbitrary operating frequencies $\mathrm{f}_{\mathrm{L}}$ and $\mathrm{f}_{\mathrm{U}}$. A general relationship between electrical length $\theta_{\mathrm{L}}$ and operating frequencies $\mathrm{f}_{\mathrm{L}}$ and $\mathrm{f}_{\mathrm{U}}$ is given by

$$
\theta_{L}=\frac{\pi}{1+\frac{f_{U}}{f_{L}}}
$$

For $Z_{2}=Z_{c}$ and $\theta=\pi / 2$, the structure become equivalent to the $\lambda / 4$ branch line in conventional WPD with operating frequency $f_{M}$ where the input impedance of short/open stub becomes infinity. [4]The T-stubs corresponds to dual band. Thus the cascaded structure together obtains a tri-band operation. The middle frequency $\mathrm{f}_{\mathrm{M}}$ can be expressed as the mean value of the other two operating frequencies $f_{L}$ and $f_{U}$.

$$
f_{M}=\frac{f_{L}+f_{U}}{2}
$$

[5]Figure 4 shows the line impedances varying with the frequency ratio of $f_{U} / f_{L}$, which can be used as the design chart of the proposed divider. As shown, the line impedance $Z_{2}$ exhibits gradual increase with the frequency ratio, while the stub impedances $Z s$ and Zo increase rapidly. In general, the short stub $Z s$ has smaller impedance than the open stub $Z o$ and can then be used for higher frequency ratios. Assuming that the available line impedance values are limited between 15 and $120 \Omega$, the maximum frequency ratio range can then be estimated as $2.8<f_{U} / f_{L}<4.1$ for the extended T-shaped short stub structure and $2.2<f_{U} / f_{L}<2.8$ for the open stub one.

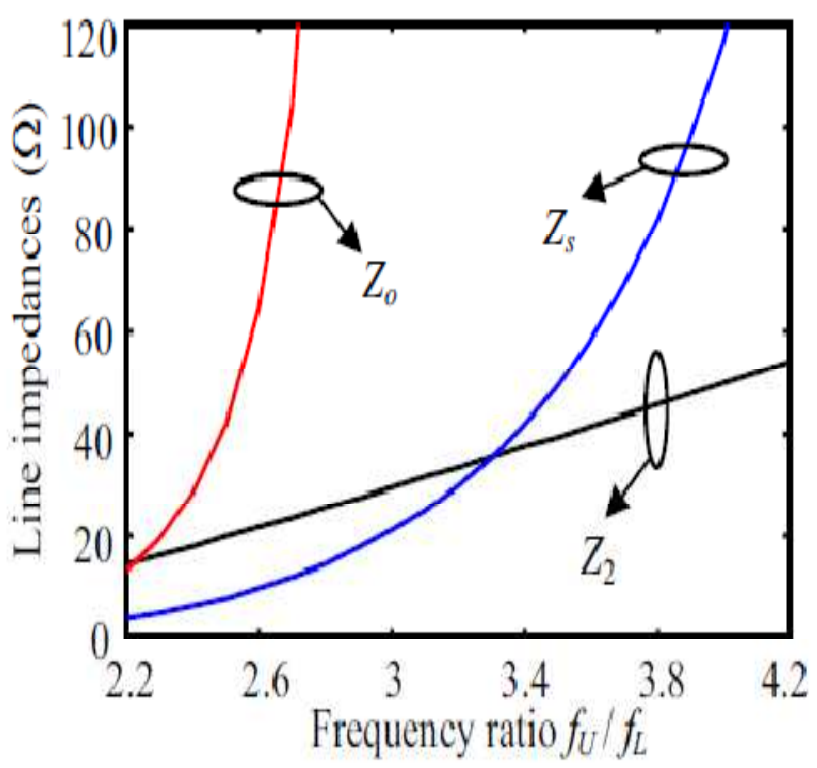

Fig -4: Line impedances Vs frequency ratio $f_{U} / f_{L}$

\section{DESIGN PROCEDURE}

The design procedure can be described using a flowchart as below:

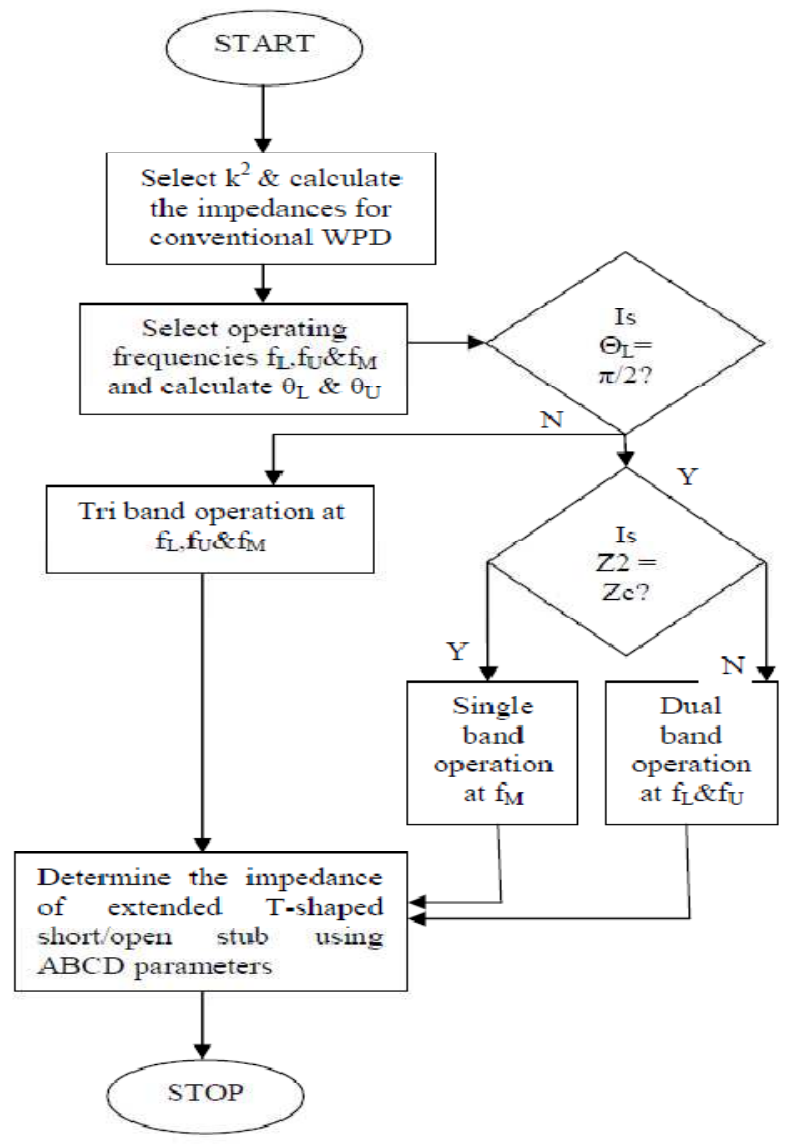

\section{RESULTS}

Two different unequal tri-band Wilkinson power dividers, one with the short stub structure and the other with the open stub structure, are designed and compared. The frequency ratios $f_{U} / f_{L}$ are chosen to be 3.62 and 2.50 for short stub structure and open stub structure, respectively. The extended T-shaped short/open stubs are designed in microstrip circuit at frequencies 1.3, 3.0 and 4.7 GHz. The Substrate thickness and dielectric constant is chosen to be $\varepsilon_{\mathrm{r}}=3.55$ and $\mathrm{h}=0.813 \mathrm{~mm}$. The calculated design parameters are listed in the below table.

Table -1: Calculated electrical lengths and impedances of the two different designs

\begin{tabular}{|c|c|c|c|c|}
\hline Extended line & \multicolumn{2}{|c|}{$\begin{array}{c}\text { T-shaped short } \\
\text { stub }\left(\mathrm{f}_{\mathrm{U}} / \mathrm{f}_{\mathrm{L}}=3.62\right)\end{array}$} & \multicolumn{2}{c|}{$\begin{array}{c}\text { T-shaped open } \\
\text { stub }\left(\mathrm{f}_{\mathrm{U}} / \mathrm{f}_{\mathrm{L}}=2.5\right)\end{array}$} \\
\hline $\begin{array}{c}\mathrm{Z}_{\mathrm{cl}}=\mathrm{Z}_{21}=102.99 \Omega \\
\Theta=19.5^{\circ}\end{array}$ & $\begin{array}{c}\mathrm{Z}_{11}=69.65 \Omega \\
\Theta=39^{\circ}\end{array}$ & $\begin{array}{c}\mathrm{Z}_{12}=30.32 \Omega \\
\Theta=39^{\circ}\end{array}$ & $\begin{array}{c}\mathrm{Z}_{11}=29.53 \Omega \\
\Theta=39^{\circ}\end{array}$ & $\begin{array}{c}\mathrm{Z}_{22}=14.76 \Omega \\
\Theta=39^{\circ}\end{array}$ \\
\hline $\begin{array}{c}\mathrm{Z}_{\mathrm{c}}=\mathrm{Z}_{22}=51.49 \Omega \\
\Theta=19.5^{\circ}\end{array}$ & $\begin{array}{r}\mathrm{Z}_{\mathrm{s} 1}=86.88 \Omega \\
\Theta=39^{\circ}\end{array}$ & $\begin{array}{r}\mathrm{Z}_{\mathrm{s} 2}=43.44 \Omega \\
\Theta=39^{\circ}\end{array}$ & $\begin{array}{c}\mathrm{Z}_{\mathrm{0} 1}=68.98 \Omega \\
2 \Theta=78^{\circ}\end{array}$ & $\begin{array}{c}\mathrm{Z}_{\mathrm{O} 2}=34.49 \Omega \\
2 \Theta=78^{\circ}\end{array}$ \\
\hline
\end{tabular}


Figure 5 shows the simulation results of both the extended T-shaped structures. It is found that the short stub structure exhibits better performance in all the three operating frequencies. At the first design frequency, the $f_{L}=1.3 \mathrm{GHz}$, the measured $|\mathrm{S} 11|=-25.25 \mathrm{~dB},|\mathrm{~S} 21|=-4.98 \mathrm{~dB},|\mathrm{~S} 22|=-$ $15.287 \mathrm{~dB}$ and $|\mathrm{S} 23|=-42.36 \mathrm{~dB}$. At $f_{M}=3.0 \mathrm{GHz}$, the measured $|\mathrm{S} 11|=-26.355 \mathrm{~dB},|\mathrm{~S} 21|=-5.02 \mathrm{~dB},|\mathrm{~S} 22|=-$ $14.97 \mathrm{~dB}$ and $|\mathrm{S} 23|=-36.69 \mathrm{~dB}$. At $f_{U}=4.7 \mathrm{GHz}$, the measured $|\mathrm{S} 11|=-22.61 \mathrm{~dB},|\mathrm{~S} 21|=-5.08 \mathrm{~dB},|\mathrm{~S} 22|=-15.28$ $\mathrm{dB}$ and $|\mathrm{S} 23|=-29.95 \mathrm{~dB}$. Over these three operating frequencies, the measured return losses are better than -25 $\mathrm{dB}$ at all three ports.

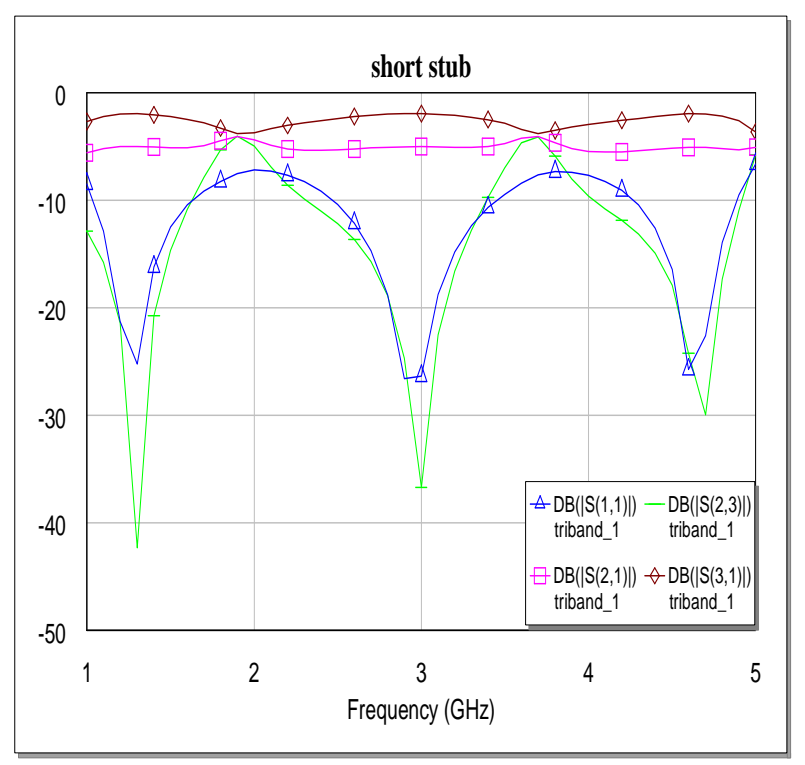

(a) Short stub

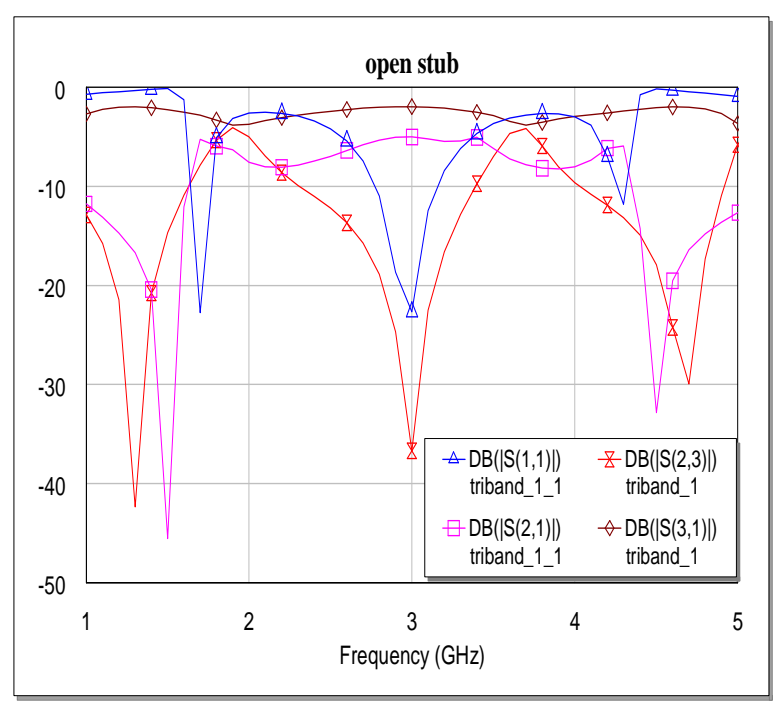

(b) Open stub

Fig -5: Calculated S-parameters of the tri-band unequal WPD sing extended T-shaped (a) short $\operatorname{stubs}\left(f_{U} / f_{L}=3.62\right)$ (b) open stubs $\left(f_{U} / f_{L}=2.50\right)$.

\section{CONCLUSIONS}

An unequal Wilkinson power divider which can operate in three different frequencies has been proposed by using the extended T-shaped short/open stub structure. The design equations for both the structures are derived. The simulation results shows that the short stub structure exhibits better frequency response characteristics than that of open stub structure.

\section{REFERENCES}

[1]. Design of Unequal Wilkinson Power Divider for triband operation. C. Miao1, B. Li1, G. Yang1, N. Yang2, C. Hua1, and W.Wu1, Progress In Electromagnetics Research Letters, Vol. 28, 159-172, 2012

[2]. A Tri-Band Wilkinson Power Divider Using Extended T-Shaped Stubs, Bo Li1, 2, Xidong Wu, Changzhou Hua1, 2, Nan Yang1, Daohong Zhu1, and Wen Wu, CJMW2011 Proceedings.

[3]. D.M. Pozar, Microwave Engineering, 3rd edition, New York: Wiley 2005.

[4]. Dual Band Wilkinson Power Dividers Using T-Sections, Ashraf S. Mohra and Majeed A. Alkanhal, Journal of Microwaves, Optoelectronics and Electromagnetic Applications, Vol. 7, No. 2, December 2008

[5]. Li, B., X. Wu, C. Hua, N. Yang, D. Zhu, and W. Wu, \A novel tri-band Wilkinson power divider using extended $\mathrm{T}$ shaped stubs, "China-Japan Joint Microwave Conference, 322-324, Hangzhou, China, 2011.

\section{BIOGRAPHIES}

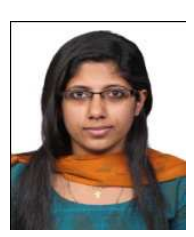

Sandra Brigit Johnson received Bachelor's degree in Electronics \&Telecommunication Engineering from Sathyabama University, Chennai, Tamil Nadu during the year 2008'12.Currently she is pursuing Master's in Communication Engineering from VIT University, Vellore, Tamil Nadu.

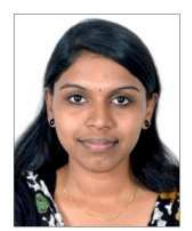

Saranya Nath P received Bachelor's degree in Electronics \& Communication Engineering from TKM Institute of Technology, Kollam, Kerala during the year 2008-'12.Currently she is pursuing Master's in Communication Engineering from VIT University, Vellore, Tamil Nadu. 